\section{Movimientos sociales en España de la Transición hasta nuestros días: ¿por un cambio del sistema o por un cambio en el sistema?}

\section{Social movements in Spain from the transition until today: a change inside the system or changing the system?}

\author{
Asier Tapia \\ asier.tapia@ciiactua.com \\ Centro de Investigación Internacional ACTUA \\ España

\section{Miguel Hernández} \\ mhg.miguel@ciiactua.com \\ Centro de Investigación Internacional ACTUA \\ España
}

Articulo recibido: 15/10/2013

Artículo aprobado: 2/12/2013

Para citar este artículo: Tapia, A. \& Hernández, M. (2013). Movimientos sociales en España de la Transición hasta nuestros días: ¿Por un cambio del sistema o por un cambio en el sistema? Ciudad Paz-Ando, 6(2), pp. 48-63

Estudiante de Doctorado por la Universidad de Deusto en Estudios Internacionales e Interculturales. Máster en Cuestiones Contemporáneas de Derechos Humanos por la Universidad Pablo de Olabide. Máster en Estudios Internacionales por la Universidad del País Vasco.

2 Licenciado en Derecho y Ciencias Políticas por la Universidad Carlos III de Madrid. Postgrado de Especialización en Aptitud Pedagógica por la Universidad Complutense de Madrid Experto Universitario en Gestión y Prevención de Crisis Internacionales por la Universidad Carlos III de Madrid Máster en Acción Solidaria Internacional de Europa por la Universidad Carlos III de Madrid

\section{Resumen}

Los movimientos sociales en España desde la Transición Democrática han fortalecido progresivamente la conexión entre sus actividades y su capacidad efectiva de incidir en la vida pública. Nuevos movimientos contestatarios emergentes se conforman ante los retos y desafíos de la crisis que vivimos en la actualidad. La dificultad de concluir definitivamente si estos movimientos españoles confluyen con un cambio análogo a nivel global se solapa con la dificultad de discernir si pretenden un cambio en el sistema nacional o que cambie el sistema en sí. El tiempo transcurrido es escaso para tan grandes afirmaciones.

Palabras Claves: Transición, crisis, movimientos sociales, participación, reforma, incertidumbre

\begin{abstract}
Since the Democratic Transition, social movements in Spain have progressively strengthened the connection between their activities and their effective capacity to influence public life. New protest movements are conformed in the presence of the emerging challenges of the crisis we live in nowadays. The difficulty of knowing if these Spanish movements converge with a global change overlaps with the complexity of distinguishing whether or not they are willing to a national system transformation or the modification of the system itself. Only time will be able to offer answers.
\end{abstract}

Key Words: Transition, crisis, social movements, participation, reform, uncertainness 
U na revisión general del panorama político y económico en que surgen y evolucionan los movimientos sociales en el Estado Español desde el final de la dictadura franquista y a lo largo de la transición y posterior consolidación democrática, permite comprender el origen y desarrollo de los movimientos sociales emergentes en el actual contexto de la crisis económica, política, cultural y de valores. A continuación se resumen brevemente los aspectos de mayor relevancia en la conformación de los movimientos sociales apuntados, con el ánimo de contribuir a la comprensión del sentido y alcance posible de los procesos de contestación social organizada que aparecen recientemente a partir de la crisis por la que atraviesa la sociedad española.

\section{De la transición al bienestar}

La Transición a la democracia en España ha venido siendo analizada por la ciencia política como una reforma pactada en un contexto en que la sociología política moderna se acercaba al centro ideológico. "El modelo de transición pactada contempló un acuerdo tácito entre las elites acerca de la necesidad de desmovilizar a la sociedad para asegurar una transición política exitosa, de acuerdo a su visión de la misma" (Jiménez \& Calle, 2007). Respondiendo al espíritu general de superación definitiva de las diferencias, se imponen la moderación y el centrismo, superándose las diferencias entre falangistas y nacionalcatolicistas por un lado, y anarquistas o comunistas por el otro ${ }^{3}$

\footnotetext{
3 El primer presidente democráticamente electo, Alfonso Suárez, al frente del partido de centro-derecha, Unión de Centro Democrático, UCD, legalizó el Partido Comunista. A finales de los años 70 había un número significativo de comunistas en el territorio español, el cual no tendrá, sin embargo, igual reflejo en la conformación parlamentaria. Integrados en la fuerza política Izquierda Unida (IU), los comunistas, así como otros grupos minoritarios y más cercanos a los extremos del segmento político, acusarán un notable descenso
}

Antes del final del régimen, durante el llamado tardo-franquismo, la sociedad española supera la oposición oligarquía-proletariado, característica de un país meramente rural o campesino. A partir de mediados de los años 60 comienza a sentirse un progresivo aperturismo económico, acompañado de tímidas reformas y mejoramiento de la condición social de los ciudadanos ${ }^{4}$. La clase media y un sector empresarial comienzan a emerger progresivamente, favoreciendo la posterior superación del "atraso español". Se puede afirmar que es este despertar económico y social de los pueblos españoles una de las condiciones necesarias que permite la posterior transición democrática apoyada en la competencia centrípeta que inspira el proceso ${ }^{5}$. Esto es, se trataba de converger hacia la fraternidad suficiente, ánimo que habría de impregnar tanto los esfuerzos de la política como los sociales en los tiempos de la transición.

Con respecto a los movimientos sociales, el carácter pactista que marca los primeros años de la transición democrática y la aproximación ideológica y programática de los partidos políticos relaja notablemente su desarrollo organizado y alcance general. Las posibilidades de participación ciudadana eran bastante limitadas en la práctica, y las reivin-

progresivo de su representatividad electoral conforme transcurren las sucesivas elecciones generales, castigados en cierto modo y de manera creciente por un régimen electoral favorecedor del bipartidismo y que llevaba al PSOE principalmente a la apelación al voto útil en la oposición conjunta de los potenciales votantes de la izquierda contra la derecha

4 Durante las dos primeras décadas del régimen del General Franco el modelo de Estado fue marcadamente autárquico, prolongando entre buena parte de la población las miserias de la postguerra e imposibilitando la acción general de los movimientos sociales. Sin embargo, las posibilidades de estabilidad nacional y competitividad estratégica española se veían muy limitadas en medio de autoritarismo franquista, cuya continuidad no se veía favorecida por el contexto de relaciones internacionales, de crecimiento económico y democratización política

5 El pueblo evidenció haber interiorizado la comprensión de los efectos negativos de una excesiva polarización y confrontación socio-política que en el pasado hubo enrarecido hasta la sangre la vida común, decantándose por el centro político y social en el proceso histórico apuntado. 
dicaciones y demandas sociales se vieron absorbidas por la agenda e institucionalidad política con relativa comodidad. No obstante lo anterior, por la importancia que tiene en lo que respecta a la promoción popular de la participación democrática, resulta interesante el caso del Movimiento Vecinal. A pesar de ver limitar sus exigencias a la prestación de servicios públicos locales destinados a grupos concretos de beneficiarios, o aún cuando suelen presentar un gran sesgo político y una notable falta de identidad colectiva, el hecho de que representen, ciertamente, experiencias válidas de organización asociativa desde la base de la ciudadanía hace que estos movimientos destaquen como promotores de la participación, elemento fundamental del Estado Social y Democrático de Derecho proclamado por la Constitución Española de $1978^{6}$. De otra parte, el Movimiento por la Objeción de Conciencia (MOC), insumiso al servicio militar obligatorio creado en 1977, y las propuestas de desobediencia civil suponen otra base importante de reivindicación social cuyo influjo permanecerá hasta la aparición de los mencionados movimientos más recientes.

Progresivamente se va consolidando el modelo bipartidista, en donde el Partido Socialista Obrero Español (PSOE) y el Partido Popular (PP), se alternarán sucesivamente el Gobierno. Enfrentar la ley electoral que favorece esta dinámica, perjudicando a las fuerzas minoritarias, será una de las principales reivindicaciones latentes que cobra toda su fuerza en los movimientos sociales más actuales. El enfoque de los movimientos sociales, así como su interlocución con las autoridades gubernamentales, aparecen sujetos a las

6 "España se constituye en un Estado social y democrático de derecho, que propugna como valores superiores de su ordenamiento jurídico la libertad, la igualdad, la justicia y el pluralismo político", Artículo 1 de la Constitución Española de 1978. coyunturas y programas políticos en curso. En ese sentido, la temprana consideración de la cuestión de igualdad de género por parte de los sucesivos gobiernos favorecerá, por ejemplo, la presencia prevalente del movimiento feminista en las agendas políticas, y su mayor institucionalización con respecto a otros movimientos. En todo caso, las numerosas reformas que introduce el gobierno socialista a partir de $1982^{7}$, permiten una respetable presencia de las demandas sociales en los asuntos de la gestión pública.

La llegada del gobierno del PP es relativamente dulce, acomodándose a la estabilidad bipartidista. Durante el mandato de José María Aznar continúa el crecimiento económico como esa gran fuerza capaz de aunar en un horizonte único las metas del desarrollo tan ansiadas tanto por los liberales defensores del libre mercado como por los partidarios de una mayor intervención pública. Se prolongan las reformas iniciadas por los gobiernos anteriores en medio de una coyuntura económica regional internacional que continúa siendo favorable ${ }^{8}$. En este contexto, con la llegada de millones de inmigrantes se conforma rápidamente, como nunca antes, una sociedad multicultural y cosmopolita en España, la cual motivó reacciones políticas oportunistas e impopulares, y sentimientos controvertidos entre la sociedad. Pese a todo, se deja notar un descontento social creciente; por ejemplo, el elevado abstencionismo con que el primer gobierno popular de José María Aznar ganó las

El presidente socialista Felipe González reordenó todo el sistema de producción y economía nacional. Esto es, en un contexto de integración en la Comunidad Económica Europea CEE en 1986, más adelante Unión Europea en 1992, se supera, en términos generales, todo aquello que no resulta competitivo internacionalmente, por ejemplo, dejando de lado los obsoletos altos hornos, la minería naviera, los astilleros y demás industria caduca de los años setenta.

8 Con los fondos comunitarios para la agricultura y para la infraestructura, culmina la sorprendente transformación de España, que vive sus años felices con el desarrollo del Estado de Bienestar. 
elecciones, hace que los movimientos sociales continúen, por lo general, sucediéndose y profundizando el alcance de sus reivindicaciones, las cuales apuntarán progresivamente a transformar el modelo político implantado en la Transición. Este puede ser un objetivo incierto en la medida en que su mantenimiento puede depender esencialmente de la continuidad o no de la crisis, y del modo en que se salga de ésta.

Sin embargo, la colaboración entre movimientos sociales fue muy escasa, especialmente durante el primero de los periodos mencionados. La descentralización, el personalismo o el marcado territorialismo y localismo son elementos característicos de las protestas y reivindicaciones acontecidas durante los primeros años de la transición, que dificultaron notablemente las posibilidades de coordinación entre aquellos. Se puede observar cómo el marcado carácter temático-concreto de los diferentes movimientos sociales dificulta la consolidación de un sentimiento general de identidad colectiva y solidaridad entre ellos. Las iniciativas que desarrollaron fueron principalmente acciones puntuales, en su gran mayoría reactivas frente a situaciones indeseadas, dadas o sobrevenidas, o frente a acontecimientos, según los casos, más o menos inesperados o repentinos.

A partir de los años noventa se irán sucediendo distintas campañas, mejorando poco a poco la articulación conjunta de los movimientos sociales. Progresivamente, aún sin contarse con una infraestructura de coordinación estatal, va aumentando la identidad colectiva de los anteriores, cuyas iniciativas tienden a ser cada vez más proactivas. La acción social organizada ensancha generosamente su visibilidad pública y su capacidad de sensibilización popular gracias a un mayor empleo de medios de comunicación oficiales o alternativos, y al desarrollo de sucesivas campañas más o menos interconectadas, lo que contribuye a la concienciación democrática del conjunto de la ciudadanía. Una relativa profesionalización de los movimientos se acompaña de un aumento de los recursos de los que disponen y de un incremento de la eficiencia en la gestión de los mismos, todo lo cual redunda en la mejora de su capacidad de incidencia efectiva en la práctica política.

Superada la resaca del pactismo de la transición, comienzan a ensancharse paulatinamente los discursos y mecanismos de acción de los movimientos, acentuando la descentralización previa pero también aumentando la identidad colectiva y la coordinación entre acciones cada vez más radicales, y las propuestas de creciente capacidad operativa para el impacto y la transformación social. Para ilustrar las anteriores consideraciones y su evolución, se pueden indicar algunos de los que se van conformando y organizando progresivamente a lo largo de las décadas de los años ochenta y noventa, sin necesidad de agotar sus diferentes ámbitos de acción.

A los clásicos movimientos estudiantil, obrero, nacionalista o sindicalista, institucionalizados al inicio de la transición democrática, se suman otros muchos movimientos que van apareciendo con ocasión de, y en respuesta a problemáticas concretas que afectan a la sociedad. Entre los múltiples movimientos que hicieron y hacen presencia en España, merece ser destacada la importancia del Movimiento PacifistaAntiimperialista, así como la del Movimiento Alter-Mundialización y contra la deriva neoliberal y turbo-capitalista, los cuales tuvieron acciones concretas, contra las minas anti-persona y anti-nucleares, contra la imposición fiscal con fines militares, contra la guerra de Irak, contra las medidas adoptadas por el Fondo Monetario Internacional (FMI) y el Banco Mundial (BM); 
y a favor del desarme, y de la abolición de la deuda externa, por mencionar algunos ejemplos. Concretamente se identifica el papel de los anteriores movimientos como fundamental en el sentido de permitir el aumento de la autonomía y de la toma de decisiones asamblearia u horizontal entre la población organizada. Su impronta se deja sentir especialmente en el uso colectivo de los espacios públicos y en la recuperación de la libre capacidad de expresión política ciudadana como elementos clave que habrán de caracterizar, años más tarde, los movimientos contestatarios emergentes en el contexto de la crisis actual.

Es de destacar el valor simbólico que tiene el Movimiento de libre ocupación "Okupa", en los actuales movimientos, el cual pasa de demandar espacios para la vivienda en sus inicios a mediados de la década de los años ochenta, a reclamar, más allá de ello, "auténticos espacios para la expresión política, de fuerte contenido anti-capitalista" (Jiménez \& Calle, 2007) La ecología política y social que inspira su actividad, promovida y desarrollada popularmente, permite el despliegue de multitud de iniciativas ciudadanas, especialmente, aunque no de manera exclusiva ${ }^{9}$, aquellas de los más jóvenes. En general, se trata de espacios que, como los arraigados Centros Sociales, favorecen la aparición de alternativas llamadas a generar progresivamente una transformación contra-cultural de gran importancia en el enfrentamiento más reciente de la inequidad, en la búsqueda de la convivencia cívica y justicia social ${ }^{10}$.

\footnotetext{
9 Propuestas como las huertas urbanas, el "hazlo-tu-mismo", los espacios de libre intercambio o las manifestaciones de creación alternativa repercuten sin duda en la extensión de la concienciación y participación colectiva. Algunas de las manifestaciones no pasan de ser meras expresiones culturales o artísticas sin vocación política definida, si bien no por ello son desdeñables en términos de reinvención del modelo de vida y de sociedad.

10 Idealmente, la transformación cultural a la que apuntan los movimientos sociales toda vez organizados para trascender sus causas sobre problemáticas sociales específicas, está dirigida a
}

Debe reseñarse también el boom de las organizaciones no gubernamentales, el de las acciones de voluntariado en las más diversas temáticas, y el movimiento ecologista o ambientalista, que con diferentes frentes, como la lucha contra el cambio climático, la defensa de energías renovables o la defensa del litoral, está llamado a incidir, de forma creciente, en las políticas públicas nacionales e internacionales. Además de las anteriores, reivindicaciones sociales de importancia son las organizadas desde los movimientos anti-racista y de inmigrantes, las protestas de los afectados por el cierre de empresas, por la educación pública gratuita y de calidad, movimientos de oposición a grandes infraestructuras, entre otras luchas más puntuales.

Tan sólo tres décadas más tarde de su inicio, el modelo político y social parece cercano a su agotamiento. Las tendencias, en medio de la crisis generalizada del bienestar, social y económica, apuntan hoy a reinventar el modelo de estado y de sociedad. En todo caso, los anteriores movimientos, como ha sido puesto de relieve, tienen una repercusión destacable entre las nuevas luchas sociales que aparecen ya entrado el siglo XXI en el contexto de la crisis mencionada, desgaste y malestar generalizado.

\section{El problema económico}

Cuando la crisis económica actual se hace evidente, a partir de 2008, el problema principal aparecerá con la deuda privada al reducirse la financiación a bajo coste para los bancos, las empresas y la ciudadanía. Se habían vivido los años felices, muchas personas habiéndose comportado como nuevos ricos,

enfrentar los abusos de poder, el dirigismo de las élites o las consecuencias negativas y efectos desmedidos de la deriva neoliberal y turbo-capitalista. 


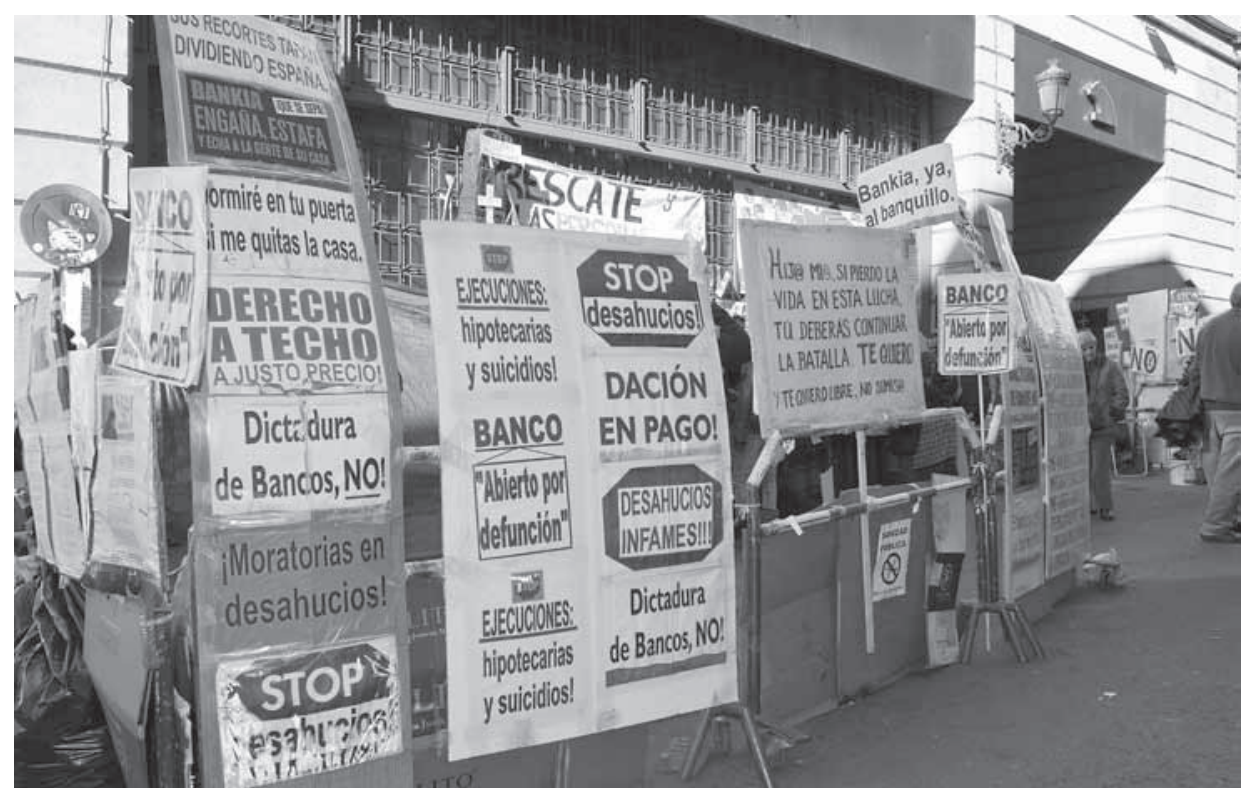

CNatursports / Shutterstock.com

de manera un tanto ingenua e inconsciente, hasta la caída de Leman Brothers, el estallido de la burbuja inmobiliaria y el fin de la fiebre de las hipotecas. Restringido el gasto público, el Estado comienza a tener cada vez menos recursos para salud, vivienda o educación y la sociedad española se ve obligada, por lo tanto, a contener el gasto ${ }^{11}$. La clase media ha sido y sigue siendo la gran afectada. En el actual contexto de crisis, el capital más fuerte resulta favorecido. Ya Fernando de los Ríos consideró en 1926, que "las crisis sirven para que el capitalismo rehaga su organismo, se vuelva más fuerte" (García del Burgo, 2013). Los millones de clientes de cada banco dependen de la estabilidad de estos para lograr la conservación de sus medios de vida. Ello motiva la adopción de políticas públicas garantistas, de apoyo a la viabilidad de las mencionadas entidades. Y así, el problema ha de ser soportado públicamente por el conjunto

11 El aumento del desempleo producto de la gran mortandad de empresas, supone a su vez un aumento del gasto público, como medida necesaria para hacer frente a crecientes necesidades de prestaciones de seguridad social y por desempleo, de manera que el Estado ha de seguir endeudándose. de la ciudadanía ${ }^{12}$. Es éste el verdadero problema y angustia de la población ${ }^{13}$.

En consecuencia, se explica el ascenso de la reprobación moral generalizada, tanto de las causas como de los causantes de la situación actual, y la confrontación social de corte crecientemente incesante, radical e infatigable. La sociedad organizada ya no tolera que la recompensa por causar la crisis y caída de las economías familiares, la pérdida del bienestar y, en suma, el empeoramiento de las condiciones de vida de los ciudadanos, sea el

\footnotetext{
12 Desafortunadamente una entidad bancaria no se puede abandonar a su suerte y dejar caer como sí a una familia. Los ahorros de los ciudadanos dependen de la salvación de los bancos. Detrás de ello se encuentra la perversión nefasta de un sistema en donde si les va mal a los que mayor capital acumulan les va peor a los que menos tienen. En ausencia de la anterior dependencia no se justificaría ni moral ni jurídicamente, en un estado ideal de las cosas, el mantenimiento de la prevalencia del interés de las entidades bancarias frente al de individuos, familias y otras pequeñas y medianas empresas, especialmente en contextos de crisis y situaciones delicadas como la actual que hacen de las priorizaciones excluyentes una necesidad política moralmente ineludible.

13 Con base a lo anterior, se puede sostener la obligación que ha de sujetar a los bancos, en relación a la debida repercusión en el conjunto de la ciudadanía de los beneficios que logre alcanzar y privilegios con que se vean beneficiados. Sin embargo, los bancos, deudores a su vez de otros bancos, no están transmitiendo en las personas, sus clientes, en forma alguna, antes al contrario, siquiera una parte de las inyecciones públicas que reciben. Las relaciones de poder y connivencia entre oligarcas, banqueros y políticos, bribones egoístas y responsables de la crisis, no permite una realidad más justa a este respecto.
} 
perdón, el olvido y hasta el favorecimiento de las condiciones evidentes que permiten que los responsables y mayores beneficiados de la crisis puedan mantener su privilegiada situación o incluso continuar su crecimiento ${ }^{14}$. ¡Si el ciudadano ha de caer, que caigan todos ellos también!, grita la voz del pueblo.

La sociedad española había estabilizado su imaginario de bienestar gracias a las medidas proteccionistas, de redistribución, y al fortalecimiento y aseguramiento de un sistema de educación, sanidad, prestaciones por desempleo, pensiones y acceso a servicios sociales públicos y de calidad. Luego del estallido de la crisis, ésta será justamente una de las consignas con que más se identificarán muchos de los movimientos sociales en España durante el último lustro, luego del estallido de la crisis: "público y de calidad", pues se trata de aquello que ahora está siendo directamente afectado, de aquellos beneficios públicos y sociales que ahora están siendo recortados, suspendidos o eliminados.

\section{Movimientos sociales en España y el Movimiento Civil Global: ¿un sólo movimiento global o una conjunción de movimientos de reivindicación nacionales?}

La aparición cuasi-simultánea de movimientos análogos o similares a nivel mundial debilitaría, al menos parcialmente, la posibilidad de que el movimiento español esté estrechamente ligado a la experiencia nacional propia y al desencanto con el sistema nacional estructurado en La Transición. Sin embargo, se debe tener en cuenta que tanto la propia

14 Lejos de pagar su deuda social, de inhabilitación permanente, de resarcimiento a la sociedad o trabajo social desde la funcionalidad e intereses legítimamente concebidos desde y para lo social; lejos de todo ello, los principales responsables de la crisis continúan enriqueciéndose sin pausa en el transcurso de la misma.
Transición Española como la consiguiente construcción de la Unión Europea responden a una estructuración global de la democracia en su versión liberal para conjugarse con los criterios económicos propugnados por los poderes fácticos que requieren de una estructura social de consumo concreta en un momento en que, a raíz del fin de la guerra fría y el "Nuevo Orden Mundial", el sistema neoliberal fue expandiéndose como nueva versión del liberalismo.

Desde tiempo atrás, la indiscutible participación de las tecnologías ha venido jugando un rol en lo que se denomina movimiento civil global, que, a diferentes niveles y temáticas, ha venido ocupando progresivamente el espacio internacional tanto informal como formal, especialmente en Naciones Unidas donde actores no estatales han ganado espacios de participación cada vez mayores, hasta retar la posición del Estado como único sujeto jurídico internacional. Estos movimientos surgidos a partir de los años setenta intentaron ganar protagonismo a medida que este sistema neoliberal iba ganando espacios en casi todos los países del mundo poniendo siempre por encima de las personas la materia y el mercado.

A este respecto, es indiscutible el ejemplo de campañas multinacionales expandidas por todo el globo, tales como la plataforma por el 0,7 \% para la ayuda al desarrollo y, desde luego, las sorprendentes movilizaciones antiglobalización neoliberal surgidas a raíz de la cumbre de Seattle de la Organización Mundial del Comercio OMC, considerada como el nacimiento de este movimiento, el cual se siguió fortaleciendo y obteniendo respuestas represivas por parte de los Estados anfitriones de cumbres de esta y otras organizaciones de mandato neoliberal. La elevada participación de asociaciones españolas puede constatar 
un aprendizaje desarrollado actualmente en términos de movilización.

Por otro lado, el movimiento contra la guerra de Irak y, en menor medida, de Afganistán supusieron ejemplos similares de grandes movilizaciones (Jiménez \& Calle, 2007); sin embargo, es difícil defender estas movilizaciones y que la mayoría de la gente movilizada buscara la lucha contra una estrategia global de defensa de unos intereses geopolíticos concretos ligados a Estados Unidos, y la necesidad de un crecimiento económico que no podía verse mitigado por una carencia de recursos fósiles a un precio adecuado para este objetivo. Si bien probablemente muchos de los organizadores eran conocedores de estas claras intenciones y buscaban acabar con ellas por medio de las movilizaciones, el No a Violencia como expresión máxima y en ocasiones simplista, sin duda supone un acicate para que muchas personas acudieran a estas movilizaciones aún desconociendo las intenciones globales de los promotores de la guerra y el intento de los organizadores del movimiento de atacar estas intenciones.

Estos ciclos de movilización supusieron un aprendizaje de grandes grupos de personas en relación con los mecanismos de reivindicación social, motivado entre otras cosas por las terribles circunstancias existentes en España. Se puede resaltar también la apropiación de otros países del movimiento 15-M o ¡Democracia Real Ya!, aunque fuera sólo nominal, sí evidencia la manera en que ciertos sentimientos eran compartidos, probablemente muy vinculados a la defensa del Estado de Bienestar, aunque atravesado por las afujías en cada uno de los contextos locales.

En relación con los movimientos sociales emergentes en la actualidad se puede sostener que las principales características que los definen son la globalidad, la desobedien- cia y la radicalización de la participación ("democrática"). Hoy en día la organización de los movimientos sociales está mucho más extendida, integrada y dispuesta a la transformación política, social, económica y cultural. A este respecto se puede sostener que con la entrada en el siglo XXI, las demandas y movilizaciones sociales se globalizaron y comenzaron a tender hacia la profundización democrática proactiva, positiva, crítica y transformadora. Abandonando la clásica moderación, aparecen nuevos medios de comunicación vinculados a las redes sociales y se desarrollan nuevas formas de acción, como las denuncias globales y simultáneas, las solicitudes masivas de paralización de medidas o políticas públicas, o la ocupación simbólica de espacios públicos, como sucedió en el caso español con el movimiento del 15-M. La tendencia actual es a la acción colectiva organizada, de práctica local y alcance global, superando la anterior falta de coordinación, organización y de representación institucional, con compromisos y acciones que mejoran las posibilidades de continuidad del trabajo de protesta social así como la creciente sensibilización ciudadana.

Del conjunto de grupos sociales emergentes, destaca la centralidad del Movimiento 15-M y ¡Democracia Real Ya! Estos aglutinan y dan cabida a una gran diversidad de horizontalidad solidaria creada y organizada desde abajo y con miras a mejorar el control sobre la gestión internacional de los mercados a escala global. Ya no se trata únicamente de la izquierda frente a la derecha sino también de los de abajo frente a los de arriba, como se menciona más adelante. La sociedad se acerca a su dignidad en la medida en que sus grupos, movimientos y manifestaciones colectivas son capaces de convertir, con autonomía, libertad y en condiciones de igualdad, 
los dichos en hechos, las intenciones declaradas en acciones prácticas efectivas.

Es indiscutible la relación directa entre la aparición de movimientos como el 15-M o ¡Democracia Real Ya! y la Plataforma de Afectados por la Hipoteca (PAH). La crisis económica y todos sus males, han afectado directamente a la sociedad, destacando la especial virulencia en términos de paro por parte de los jóvenes que si bien no son los únicos, se puede aseverar que son mayoría en este tipo de movimientos sociales, con la excepción de la PAH. La respuesta de España y de la mayoría de gobiernos europeos ha sido unánime en términos de poner fin al estado de bienestar, provocando un rechazo social creciente que no presentaba mejora alguna en términos de reducción de paro que pudiera atenuar la crisis.

Entre la conformación de varios de estos grupos y otros como Los Indignados (que en Colombia se conocen como Embejucados, aportando un punto irónico-exigente más), existe sin duda una gran heterogeneidad en diversos aspectos de su composición que impide un análisis detallado para obtener unas conclusiones generales claras. Sin embargo, observar este tipo de movimientos ligándolos sólo a la crisis y obviando el sustrato previo puede suponer un grave error de cara a realizar cambios necesarios para la sociedad española y en especial para su juventud, con el objetivo de mejorar su situación o simplemente de evitar una ruptura social que pudiera ser definitiva.

La relación directa entre la crisis y el estallido social pudo suponer sólo el acicate final a un malestar existente en la sociedad, con una gran variedad creciente de motivos que se venían acumulando desde un incierto tiempo atrás, y los cuales en un determinado momento produjeron esta explosión de participación a diferentes niveles, a todas lu- ces inesperada en términos de magnitudes. No hay duda de que en todos o muchos de estos grupos se han sumado desde un inicio personas cercanas a organizaciones civiles reivindicativas menos numerosas que existían antes de la crisis y cuya ideología está ligada a proyectos políticos de izquierda que puedan o no estar vinculados a los partidos políticos.

Al interior de estos nuevos movimientos ha habido también muchas críticas acusando a estas personas, y las organizaciones que pudieran estar detrás, de instrumentar políticamente estos nuevos movimientos emanados, según estos críticos, de la nada y en beneficio propio (comprendido normalmente como beneficio político partidista). Sin embargo, la suma de otra gran cantidad de personas que hasta ese momento no se movilizaba nunca, o por lo menos no tan asiduamente, ha sido una de las grandes innovaciones, y ha producido un impacto de tal magnitud que les han llevado a protagonizar portadas de mass media a lo largo de todo el mundo. No cabe duda tampoco de que las nuevas tecnologías han propiciado un fuerte impulso a la participación al reducir drásticamente los tiempos necesarios para convocar a muchedumbres. Esto se refleja de forma más evidente en el caso del intento de bloqueo ante ejecuciones (expulsiones) hipotecarias o ante movimientos de respuesta contra la represión policial.

Este encuentro entre personas más o menos comprometidas, ha propiciado críticas sustanciales que se reflejan incluso en el nombre de alguno de estos grupos, como es el caso de Los Indignados, emanados del libro "Indignez-vous" original en francés de Stéphane Hessel en 2010, y traducido de forma sencilla como "Indignaos"(Hessel, 2010). La crítica se debe a que este grupo abstracto de indignados ve atacado, con la crisis, un ideal de vida que se había creado en el imaginario 
particular así como en el colectivo, y cuyos fundamentos elementales suponían un consumo desenfrenado de todo tipo de productos, especialmente los de tecnología. De esta manera, a menudo se dejaban de lado cuestiones de compromiso para con los menos favorecidos, quienes habían sido invisibilizados de forma más o menos consciente por parte de grandes grupos mediáticos ligados a otras corporaciones empresariales interesadas en la imagen de felicidad absoluta. Ello les convierte en objeto de críticas internas por parte de aquellos que venían siendo partícipes de movilizaciones desde antes del comienzo de la crisis y que deseaban una mejora no tanto en la calidad de vida propia, sino en la calidad de vida de los menos favorecidos. Estas personas se hubieran podido agrupar bajo el nombre de Los Comprometidos; sin embargo, el término no cuajó como los anteriores quizás por sus emanaciones excluyentes. Curiosamente el autor citado previamente, Stéphane Hessel, un año después, producto quizás del análisis y de la observación de estas disputas y de la vacuidad de la simple indignación sin sustrato ideológico, redacta otro libro manifiesto solicitando un compromiso por parte de la gente movilizada en su nuevo Engagez-vous, traducida al español como "Comprometeos"(Hessel, 2011).

A pesar de estas diferencias al interior de los grupos y lo que haya llevado a cada persona a movilizarse, todo hace pensar que estos grupos los conforman personas con grandes discrepancias con el poder político-económico del país, quienes están dispuestos a provocar un cambio a raíz de la multiplicación del malestar producido por la crisis que, como decíamos antes, supuso la gota que colmó el vaso de una buena parte de la población. No obstante, es muy posible que esta no sea la única causa, ni incluso la primordial, que haya podido producir estas movilizaciones. Si observamos la desconexión creciente entre la clase político-empresarial y el pueblo, han nacido simplificaciones de lo que en otro momento se pudo llamar "lucha de clases", y que, como ya fue expuesto previamente, hoy se expone más como confrontación entre Los de arriba y Los de abajo.

Otro de los puntos destacables es que, por ejemplo, organizaciones tradicionales como los sindicatos, también han sido objeto de furibundas críticas por parte de estos nuevos grupos que les consideran parte del sistema objeto de la crítica, objetándoles casi una instrumentalización por parte de los detentadores del poder, para presentarles como válvula de escape para las protestas laborales. A este respecto, se les ha tratado de dibujar como aprovechados que se servían de unos privilegios derivados de la conquista de derechos laborales y sindicales que el resto de trabajadores no tienen, y que en ocasiones puede tener un cierto sustrato argumentativo fundamentado en prácticas poco honestas por parte de algunos de los miembros de estas asociaciones laborales.

No obstante, esta apropiación de los sindicatos por parte de personas deshonestas con el fin de perseguir intereses individuales, es responsabilidad también de toda la sociedad, y de muchos trabajadores que se habían desinteresado por cualquier tipo de lucha cuando la economía parecía ir adecuadamente y la calidad de vida de muchos de ellos parecía mejorar, lo cual les permitió aprovecharse de su condición de sindicalistas. Sin embargo, como veremos en las propuestas de Democracia Real, ya no hay ninguna referida a este tipo de discusiones, probablemente debido a la dificultad de lograr cualquier tipo de acuerdo al respecto y comprendiendo que las referencias al au- 
mento de la transparencia debería ser suficiente para la mejora en el control de estos instrumentos.

Es necesario conocer si el objetivo final es cambiar estructuralmente el sistema conformado por la Transición o si, por el contrario, tan pronto haya un nuevo crecimiento económico más o menos prolongado (si cupiera), estas movilizaciones, indignaciones y compromisos de difuminarán junto a él. Otro de los puntos a analizar es conocer hasta qué punto la discrepancia está relacionada con la estructura del Estado únicamente, o es ejemplo de una discrepancia con el sistema-mundo liberal.

Algunos autores ya hablan de que la misma salida de la Transición fue poco más que una salida pactada para que nada cambiara, lo que en una coyuntura de ruptura como la actual sólo puede derivar en un intento de asaltar el sistema para no cometer los mismos errores que entonces.(Miquel \& Campos, 2013).

\section{¡Democracia Real Ya! y sus propuestas: una respuesta al fin del Estado de bienestar o una ruptura con un modelo social y de Estado agotado}

El mismo nombre ¡Democracia Real Ya! es sin duda muy significativo y de él extraemos la conclusión de qué se siente cuando en una democracia liberal, la palabra democracia no corresponde con el concepto que sus integrantes tienen de ella; esto es mayor participación del pueblo como sujeto directo de la democracia. Esta ruptura con un modelo de democracia supone un desapego con el modelo de Transición en cuanto forma de organización local, pero también contra un modelo
A raíz de la evidencia del concepto, es interesante exponer de qué manera se comprende que pudiera haber una democracia real o más real que la existente en España hasta ese momento, y en qué puntos sus reivindicaciones van más ligadas a cambios estructurales nacionales y/o internacionales. Uno de los elementos que más emana directamente de la crítica a la democracia es el desapego a los actuales representantes máximos de la misma como son los políticos, ya sean del nivel autonómico, municipal, nacional en sus diversas cámaras, y regional. Para ello, vamos a estudiar las propuestas que aparecen en su página web de manera sintética.

El apartado Eliminación de los privilegios de la clase política, cuyo nombre deja más que claro su objetivo, incluye varios tipos de medidas acordadas como la supresión de privilegios fiscales a la inviolabilidad parlamentaria, la publicación del patrimonio de todos los mandatarios políticos y la reducción de los cargos de libre disposición, informalmente denominados "Los Enchufados".

Esta es una medida evidentemente nacional que evidencia, además del hartazgo con la clase política española, un imaginario que la vincula con la corrupción y todo tipo de prácticas oscuras de las que se valen mediante los privilegios aprobados en las mismas instituciones democráticas.

En el penúltimo de los apartados (el último es Reducción del gasto militar, y no cuenta con explicación adicional) sobre Libertades ciudadanas y democracia participativa, podríamos decir que se condensan las reformas estructurales que hubieran podido llevar al nombre del grupo, Democracia Real Ya. En las propuestas dentro de este epígrafe se observa que supone un pequeño cajón de sastre en el que destaca la solicitud de referéndums para distintas cuestiones. Estas cuestiones 


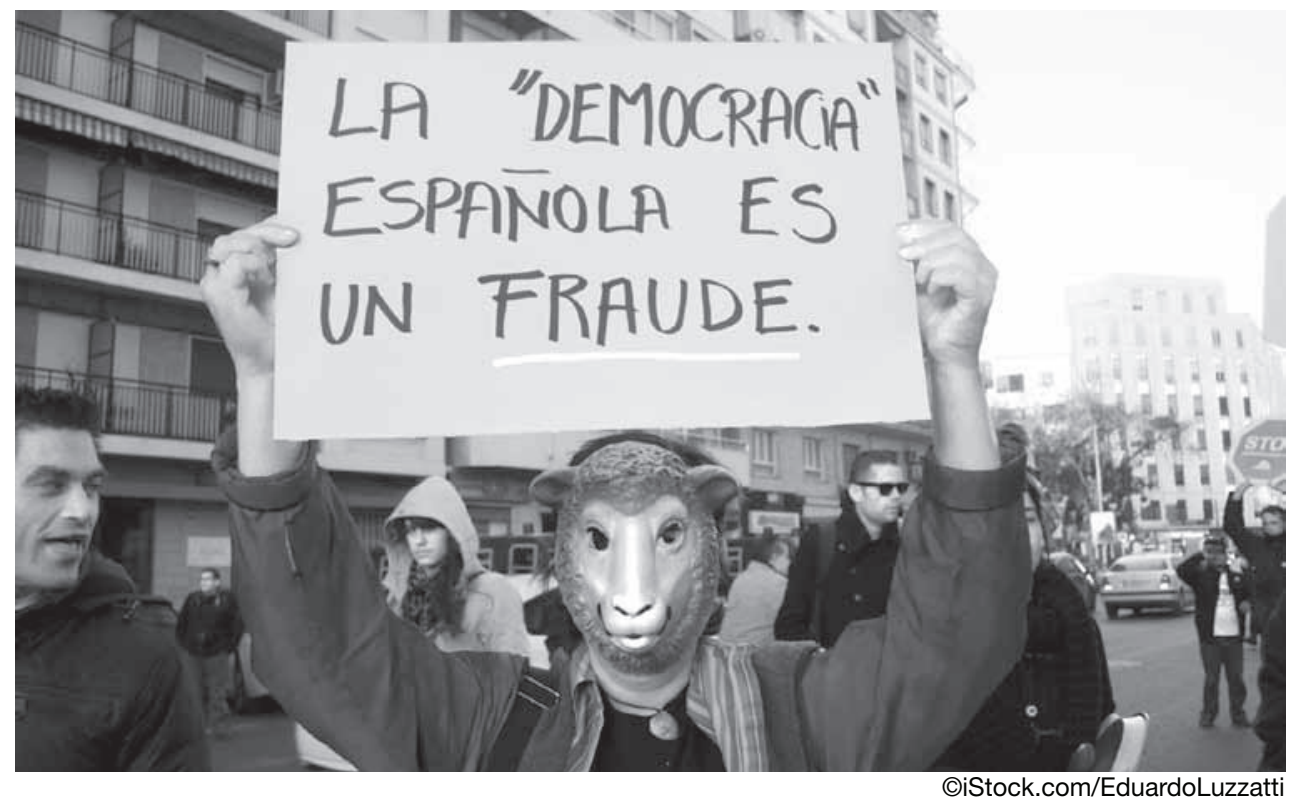

pueden ser "[...] de gran calado que modifiquen cuestiones de vida de los ciudadanos" o para la introducción de medidas dictadas desde la Unión Europea aparentemente enfocadas hacia las medidas de austeridad que vienen dispuestas desde Bruselas determinadas por la Unión Europea. Como en la gran mayoría de propuestas, sería necesario analizar el transcurso de cómo se pretende llegar a este tipo de participación, en este caso tomado del ejemplo Suizo, y de las discusiones que han existido en relación con cada uno de estos puntos, pero se escaparía de la magnitud de este escrito.

En el apartado anterior se hacía referencia al cambio en la ley electoral referido previamente en pos de mayor representatividad a cambio de la gobernabilidad, y que incluía referencia de representación del voto nulo y en blanco dejando al descubierto, una vez más, el descontento con el sistema político existente.

Un cambio profundo o metodológico en la ley electoral supondría una modificación trascendental en el sistema emanado de la Transición ya que es cuestión fundamental para la formación de sistemas políticos y por ende, de gobierno. La ley electoral es comprendida como una artimaña derivada de estos pactos de la transición que impide o dificulta la inclusión de partidos nacionales poderosos más allá de aquéllos dos que vienen gobernando casi desde las primeras elecciones post-dictadura, con la exclusión de la victoria de la UCD cuyos miembros acabarían formando parte principalmente de la Alianza Popular de entonces, ahora denominada Partido Popular. Este sistema electoral propicia de manera clara las mayorías parlamentarias, con la disculpa de que la inclusión de muchos grupos políticos minoritarios dificultaría enormemente la gobernabilidad. Ante su crítica, los cercanos a los dos partidos mayoritarios, PP y PSOE, responden con el ejemplo de Italia, cuyo régimen electoral es radicalmente opuesto al de España y efectivamente ha provocado numerosos problemas en gobernabilidad. Sin embargo, esto no obsta para que haya innumerables posibilidades intermedias que conjuguen mejor ambas cosas que el existente en la actualidad, abocado al continuo relevo entre los dos grandes partidos. Es digno de destacar que si bien ha habido algunos inten- 
tos y consecuciones de reforma de esta ley, en la mayoría de los casos han estado directamente vinculados con medidas antiterroristas o relacionadas con la ley antiterrorista.

De cualquier forma, a menos que se modifiquen otro cúmulo de cosas simultáneamente, el cambio en la ley electoral, en opinión de los autores, no supondría un cambio radical en la gobernabilidad del país, al estar sobrevalorado en cuanto a los efectos que podría tener para la estructura sociopolítica de la nación. No obstante, sigue siendo una muestra clara y evidente de cómo el sistema acordado en la Transición es uno de los objetivos de grupos tales como 15-M, ¡Democracia Real Ya! y Los Indignados.

En el mismo apartado sobre Libertades ciudadanas y democracia participativa, hay otras propuestas que busca reforzar o lograr la independencia judicial evidenciando, también, la distancia entre la sociedad civil y el poder judicial, el cual se cree responde más a los intereses de los poderosos y los políticos que lo han cooptado, que a una impartición de la justicia sin influencias políticas. Ello indirectamente es un ataque a la Constitución y por ende a la Transición, en cuanto el modo de alcanzar los tribunales más decisivos (véase Tribunal Constitucional o Tribunal Supremo) está influido de manera excesiva hacia el reparto en las cámaras de estos puestos que finalmente recaen en miembros cercanos a los partidos mayoritarios PP y PSOE.

Si bien el rechazo al sistema económico neoliberal ha hecho eco de muchas de las críticas de estas organizaciones, con especial dedicación a medida que los desahucios aumentaban y se comprendían como parte de un sistema que ponía el beneficio y el interés por encima de la persona, podríamos decir que se confunde en ocasiones con un recha- el talante de las propuestas aun se confía en darle un rostro humano. A este respecto, sin duda se evidenciará de nuevo la diversidad de grupúsculos que los forman, siendo más radicales probablemente aquéllos que provienen de unos movimientos de clase más reivindicativos, y existentes desde antes de la crisis. En lo que respecta a las propuestas de ¡Democracia Real Ya!, son claramente contrarias a las propugnadas por los gurús del neoliberalismo cuyas máximas son la disminución permanente de todo tipo de impuestos y la desaparición del Estado, dejándolo en cuestión residual sin llegar a proponer sistemas alternativos al liberalismo de forma explícita y centrándose más en la crítica al existente que en proponer otro.

Para ello, en el apartado relativo a la Fiscalidad proponen medidas de política nacional como la recuperación del Impuesto de Patrimonio y la eliminación de las SICAV (instrumento con cuasi nula fiscalidad para grandes fortunas con el supuesto objetivo de que no abandonen el país, o el control y lucha contra el fraude fiscal que en España se asume como muy por encima del existente en el resto de países europeos). Por otro lado, se propone también una de las pocas medidas de vocación más internacional como es la implantación de la Tasa Tobín, tema tabú para el neoliberalismo en tanto fiscaliza e impone un tributo a las transacciones financieras internacionales, gravando la libre movilidad de capitales y propugnando a la vez un control de los mismos, evitando que se produzcan salidas masivas de capitales que provoquen hechos como el hundimiento de la Libra Esterlina en 1992 a manos de George Soros, o sucesos similares en el Sudeste Asiático una década después.

En el apartado denominado Contra el desempleo, que afectaría fundamentalmente a la estructura económica, se proponen desde luego medidas radicales que si bien pueden 
no confrontar el sistema capitalista de manera frontal, lo afrontan desde una perspectiva totalmente diferente con medidas tales como el reparto de la jornada de trabajo, proposición cercana a los teóricos del decrecimiento que asumen la posibilidad de crecer permanentemente y, por tanto, de basar en este crecimiento la disminución del paro (Latouche, 2012) (Taibo, 2009). El resto de propuestas son respuestas directas a las medidas de austeridad-precariedad y recortes que los dos últimos gobiernos de PP-PSOE han aplicado a raíz de las presiones emanadas de otros miembros de la Unión Europea como Alemania y otros países del Norte de Europa ${ }^{15}$.

Otro apartado muy relacionado con el anterior, Derecho a la Vivienda, evidencia uno de los grandes focos de polémica como el estallido de la crisis económica a raíz de la burbuja inmobiliaria: el consiguiente aumento de desahucios con personas que se quedaban sin hogar a medida que el paro aumentaba y no tenían medios para seguir pagando sus hipotecas propiciando unas pérdidas insalvables para los bancos que requerían de ayudas públicas para su sostenimiento, aunque sin detener su política de desahuciar a estas personas. Ello alimenta de forma obvia propuestas como pedir que el Estado expropie estas viviendas para someterlas a alquiler protegido (por debajo de precios de mercado), ayudas a jóvenes y toda persona de bajos recursos, y permitir la dación en pago para cancelar las hipotecas a imagen y semejanza de otros países como Estados Unidos. Podemos afirmar sin lugar a dudas que son medidas que afectarían fundamentalmente al libre mercado;

15 Restablecimiento del subsidio de 426 euros para todos los parados de larga duración, imposibilidad de despidos objetivos o por causas colectivas de empresas en beneficios, jubilación a los 65 años e imposibilidad de aumentarla en tanto en cuanto no decrezca el desempleo juvenil y otros análogos http://www.democraciarealya.es/documento-transversal/ sin embargo, su fundamento básico no está emanado de épocas previas a la crisis.

Otro de los apartados, Servicios Públicos de Calidad, sin duda es producto-respuesta a las medidas de austeridad-recortes llevadas a cabo por España y todos los gobiernos de Europa. Dichos recortes implican un deterioro de la participación del Estado en todos los ámbitos de la economía y en especial de ese punto que diferenciaba a Europa del resto del mundo capitalista, es decir, el mayor desarrollo de su Estado de bienestar propiciando una menor desigualdad social y un mayor número de oportunidades para todas las personas comparativamente con otras regiones igualmente liberales. En resumen, podemos afirmar que todos están destinados a la mejora de diversos ámbitos como la sanidad, educación, el transporte público y la investigación fundamentalmente. Ello nos hace pensar que no se plantea una ruptura total con el sistema previo, en tanto que el Estado de Bienestar se tiene como objeto de confianza, se propugna por mantener el sistema capitalista que fortaleciera al Estado como garante de estos derechos siempre y cuando este realizara las reformas comprendidas como necesarias y expuestas en el resto de propuestas. Debemos tener en cuenta que de los postulados de la página web no se puede llegar a conclusiones absolutas, pero sí suponen una guía importante no sólo de los deseos del grupo en cuestión sino de las cuestiones y discusiones que se han venido llevando a cabo para lograr estos puntos.

\section{Sociedad y Estado a reinvención}

La idea de progreso, en la forma en que había venido acogiéndose popularmente, ya no es capaz de convencer y menos aún entusiasmar, en razón de la falta de garantías e 
inseguridad que transmite. Se ha acabado un periodo sin igual en nuestra historia. Desde la Revolución Industrial, salvedad hecha de los periodos de conflicto o recesión, el imaginario colectivo de las sucesivas generaciones ha sido el de medrar con respecto a sus antecesores. En su lugar, hoy aparece uno entristecido y falto de autoestima: "queremos vivir como nuestros abuelos". La política estatal está demostrando cuán bajo puede llegar a caer. Aquella democracia que se irguió al mundo con soberbia y prepotencia cae hoy presa de su propia inexperiencia evidenciada, malas prácticas y voluntades deleznables. Hoy se estila la pérdida de programa político, la improvisación, el derrotismo y la tan indeseable y molesta actitud del "y tú más". Así las cosas, en la actualidad prevalece el pensamiento que sienta de manera pesimista la reflexión que sigue: si no podemos ni mantener el Estado de Bienestar, ¿cómo entonces pensar en el progresismo competitivo?

Sin embargo, algo está cambiando y, como siempre que así sucede, las posibilidades de creatividad transformadora se reinventan y multiplican notablemente. Fruto del anterior malestar general, frente a cierto conformismo obligado prevalece el surgimiento de nuevos planteamientos sociales propositivos $e$ innovadores. El contexto actual supone cierta desafección política en el peor de los casos, o posibilidades de transformación con sentido y consecuencias muy seguramente impredecibles e incontrolables en el mejor de ellos. En lo social, supone ambivalencia y dicotomía, evidenciándose por un lado una tendencia a la merma y reducción de impulso cívico, conjugada, de otra parte, con la renovación de propuestas y potenciación del alcance e impacto de nuevos modelos y acciones reivindicativas con conciencia social y política. Ante semejante panorama, la solución que parece estar imponiéndose es la polarización del espectro político $^{16}$, que se radicaliza moderadamente acercándose al pluripartidismo, y la radicalización de las oportunidades sociales y que algunos consideran que no podrá evitar la caída del sistema ya que las fuerzas contrarias al mismo son cada vez más fuertes y sufren de una desengaño evidente (Miquel \& Campos, 2013).

La incertidumbre sobre el futuro y la crisis cultural conviven, como se ha apuntado, con cierto otro impulso creciente por el compromiso y la participación ciudadana ${ }^{17}$. Un tercio de la población adulta española está afiliada a una o varias asociaciones (Alberich, 2007). Así, los movimientos sociales ocupan una posición de renovado protagonismo, recobran capacidad de incidencia e impacto, marcando tendencia en el devenir del conjunto de la ciudadanía y están llamados a redefinir el modelo de Sociedad y de Estado en el futuro más inmediato. Sea como fuere, parece que la salvación, en el actual contexto de crisis, ha de venir de todos, de la participación activa de toda la ciudadanía en los asuntos de interés general bajo unos principios y forma de organización hasta ahora no conocida o permitida.

\section{Conclusiones}

Los movimientos sociales en España a raíz de la crisis han logrado cotas de participación más que en cualquier otro momento histórico previo, en el que la inmovilidad estaba determinada por un aparente periodo de bienestar y progreso. Ello no implica, sin embargo, que

\footnotetext{
16 Hoy se reinventan las opciones y posiciones de la izquierda cuando resurge la extrema derecha.

17 Así las cosas, la recuperación del protagonismo de la sociedad civil y su acercamiento al Estado, aún como utopía racional imperfectible, preconizada o promovida con ahínco por los teóricos del socialismo, democrático se produce, quizás en parte de forma paradójica o no de la manera que idealmente hubiera cabido esperar por la propia fuerza de un estado de las cosas, agotado o no (el devenir del liberalismo capitalista ofrecerá algún día respuesta a éste interrogante) pero, en todo caso agotador.
} 
no hubiera un creciente malestar previo hacia el sistema político y hacia el Estado, sino que las estrategias del sistema por cooptarlos estaban resultando suficientemente fuertes como para aplacar a los entusiastas de un cambio radical del mismo.

La virulencia de la crisis actual y las impopulares medidas tomadas con el objetivo de salir de ella, incomprendidas por buena parte la sociedad, unido a la fatiga con el sistema político y con las fallas derivadas de decisiones administrativas erradas, es uno de los motores principales de estas manifestaciones masivas y renacimiento del movimiento civil español, reflejado en el Movimiento 15-M y ¡Democracia Real Ya!, que han sido parte importante y alimentadora de unos movimientos internacionales análogos que evidencian un desapego del sistema neoliberal propugnado por Occidente a raíz del final de la Guerra Fría. El alcance global de cada uno de estos movimientos es difícil de pronosticar en tanto el sin fín de variables que colaboran con su enaltecimiento o hartazgo es imponderable.

La vocación crecientemente internacional de estos movimientos y su contacto permanente mediante las nuevas tecnologías no evitan que tanto en las propuestas como en las discusiones previas que llevaron a las anteriores tanto en el Movimiento 15-M como en ¡Democracia Real Ya!, se hayan caracterizado por criticar también los pilares de un sistema democrático desgastado que pare- ce estar tocando sus últimas notas, donde se evidencia que las fuerzas pueden devenir desde abajo hasta arriba en lo que algunos autores han dado en llamar glocalización de los movimientos sociales.

Lo anterior también evidencia que la misma Transición española no sea un elemento local más del establecimiento y expansión del neoliberalismo en España. Sin embargo, el deseo de cambio estructural de los movimientos reseñados aparenta un hartazgo total con el sistema democrático actual, un sentimiento a todas luces inédito. Hasta el momento, los partidos políticos presos del propio sistema han sido incapaces de encauzar ellos mismos estas solicitudes y de proponer unas alternativas que respondan a las demandas de estos grupos sociales.

El tiempo que pueda suponer la caída del sistema español actual, si este llegara a producirse, dependerá a su vez, entre otras cosas, del mantenimiento de la presión que se siga ejerciendo para su modificación, así como de la duración de la crisis económica y de la resistencia lógica que ejercerán los principales beneficiarios del mismo para su mantenimiento, incluyendo los partidos políticos mayoritarios, el sector empresarial oligárquico proveniente de las élites franquistas, el ejército o la misma jerarquía eclesiástica, así como una parte de la clase media que haga bueno el dicho de más vale lo malo conocido que lo bueno por conocer.

\section{Referencias Bibliográficas}

- Alberich,T. (2007). Contradicciones y evolución de movimientos sociales en España. Tribuna Abierta, (145),

- Calle, Á., \& Jiménez, M. (2007). Ebookbrowse. http://ebookbrowsee.net/f-1838-cultura-de-protesta-y-movilizacion-global-01-pdf-d63358506

- ¡Democracia Real Ya! (2014). Propuestas. Recuperado de: http://www.democraciarealya.es/documento-transversal/

- García, J. (2013, 14 de julio) Es una crisis sistémica y epidémica: de manzanas, huevos, epidemias y desmemoriados. Parte iii ¿cómo deseamos que sea la vida (el mundo) después de esta crisis? [Web log post]. Recuperado de: http://jesusgarciadelburgo.wordpress.com/category/ciencia/

- Hessel, S.(2011). Indignáos. Barcelona: Ed. Destino

- Hessel, S. (2011). Comprometéos. Barcelona: Ed. Destino

- Latouche, S. (2012). La Sociedad de la Abundancia Frugal. Barcelona: Icaria

- Miquel, J. \& Campos, LL. (2013). Asaltad el sistema. Madrid: Ed. Bubok

- Taibo, C. (2009). En defensa del decrecimiento. Sobre capitalismo, crisis y barbarie". Madrid: Ed Catarata 